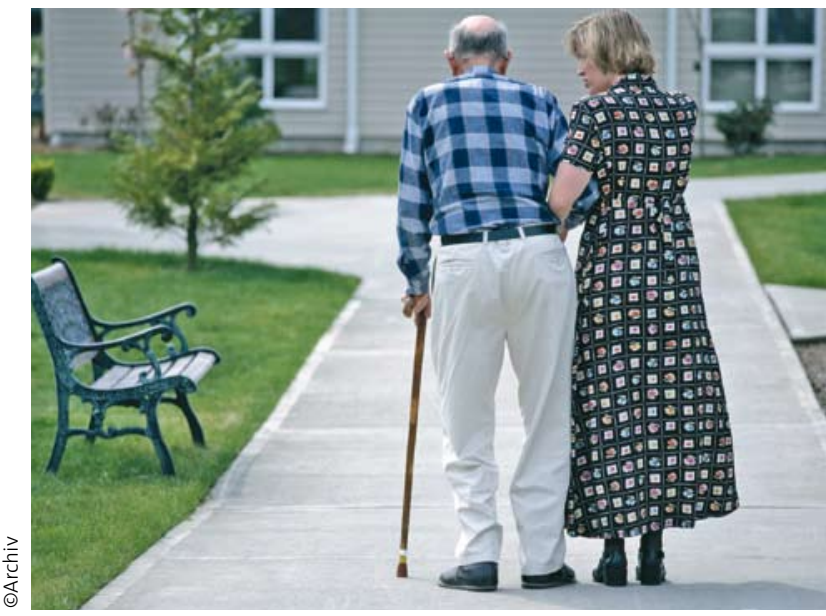

Noch sicher auf den Beinen?

\title{
Zeigt das Gangmuster das Sturzrisiko an?
}

Unterschiede im Gang sind möglicherweise ein wichtiger Prädiktor für das Sturzrisiko bei älteren Menschen.

- M. Callisaye und Mitarbeiter haben in einer Querschnittsuntersuchung in Tasmanien insgesamt 412 Personen im Alter von 60-86 Jahren hinsichtlich ihres Gangmusters untersucht. Die Probanden wurden gebeten, über eine 4,60 m lange Sensormatte zu laufen, die den Druck, der bei jedem Schritt auf die Sensoren ausgeübt wird, aufzeichnet und somit eine genaue Analyse der Schrittlänge, der Spurbreite und des Gangzyklus insgesamt zulässt (GAITRite).

Die Untersuchenden fanden eine klare Assoziation zwischen Alter und intraindividueller Gangvariabilität für fast alle gemessenen Gangparameter, mit Ausnahme der Kadenz bei Frauen.

\section{Kommentar}

Die Querschnittsuntersuchung wurde zwar repräsentativ durchgeführt, zur Evaluation der Bedeutung dieser altersabhängigen Gangveränderungen ist jedoch eine Längsschnittuntersuchung notwendig, um die Bedeutung der einzelnen Gangkomponenten im Hinblick auf ein Risikoscreening für Stürze besser abschätzen zu können. Da die gemessenen Gangparameter auch von der Gehgeschwindigkeit abhängen, empfehlen die Autoren in zukünftigen Studien unbedingt, die Gehgeschwindigkeit bei den Untersuchungen zu berücksichtigen.

T. Nikolaus a

- M. Callisaye et al.

Ageing and gait variability - a population based study of older people. Age and Ageing 39 (2010) 191-197 